\title{
Гальваномагнитные свойства пленок висмута, имеющих тонкое покрытие или подслой из сурьмы
}

\author{
(C) Н.С. Каблукова, В.А. Комаров, Д.О. Сканченко, Е.С. Макарова, Е.В. Демидов
}

Российский государственный педагогический университет им. А.И. Герцена, 191186 Санкт-Петербург, Россия

E-mail: kablukova.natali@yandex.ru

(Получена 27 декабря 2016 г. Принята к печати 12 января 2017 г.)

\begin{abstract}
Проведено исследование влияния модификации поверхностей тонких пленок висмута слоем сурьмы толщиной 10 нм. Сравнивались три типа структур на подложках из слюды: пленка висмута, слой сурьмы как подслой пленки висмута; слой сурьмы как покрытие пленки висмута. Выявлено существенное различие гальваномагнитных свойств полученных структур в зависимости от положения слоя сурьмы в структуре и толщины пленки висмута.
\end{abstract}

DOI: 10.21883/FTP.2017.07.44642.28

\section{1. Введение}

Свойства и структура низкоразмерных объектов зависят не только от состава вещества и типа структуры, но и от окружения, в котором они находятся. Наиболее значимыми являются взаимодействия низкоразмерных объектов с подложкой, переходными слоями и покрытиями различного типа [1-3].

В настоящей работе проведены исследования влияния ультратонкого ( 10 нм) слоя сурьмы на гальваномагнитные свойства текстурированных пленок висмута толщиной $\sim 90$ и $\sim 640$ нм в зависимости от его расположения: подслой или покрытие.

\section{2. Методика получения структур}

С целью решения поставленных задач были получены и исследованы три варианта структур: подложка-пленка $\mathrm{Bi}$, подложка-слой $\mathrm{Sb}$-пленка $\mathrm{Bi}$, подложка-пленка $\mathrm{Bi}-$ слой $\mathrm{Sb}$.

Все исследованные пленки были получены методом термического напыления в высоком вакууме $10^{-5}$ Торр, в одинаковых технологических режимах: температура подложки при напылении слоя висмута составляла $120^{\circ} \mathrm{C}$, а при напылении слоя сурьмы $-160^{\circ} \mathrm{C}$. Отжиг структуры проводился при температуре $250^{\circ} \mathrm{C}$ в течение 60 мин. В качестве подложек использовалась слюда мусковит толщиной 10-20 мкм.

Структура пленок исследовалась методами атомносиловой микроскопии (AСM) и выявляющего химического травления. Исследование гальваномагнитных свойств проводилось в интервале температур 77-300 К и магнитном поле до 0.65 Тл.

\section{3. Экспериментальные результаты}

\section{1. Кристаллическая структура полученных пленок}

Исследование структуры полученных тонких пленок висмута толщиной 640 и 90 нм на подложках из слю- ды мусковит показало, что они представляют собой блочный текстурированный кристалл с тригональной осью $C_{3}$ параллельной нормали плоскости пленки [4].

Анализ взаиморасположения фигур роста на поверхности пленки и АСМ-изображения поверхности пленки после химического выявляющего травления позволяет утверждать, что пленки являются блочными с размерами кристаллитов от 1 до 10 мкм.

Исследование кристаллической структуры пленки висмута, покрытой слоем сурьмы, показало, что она идентична структуре пленки висмута без покрытия. Такой результат вполне ожидаем.

Для улучшения понимания влияния подслоя сурьмы на структуру пленки висмута было проведено исследование структуры пленки сурьмы толщиной 10 нм на подложке из слюды. Как показало исследование поверхности такой пленки, на ней отсутствуют характерные

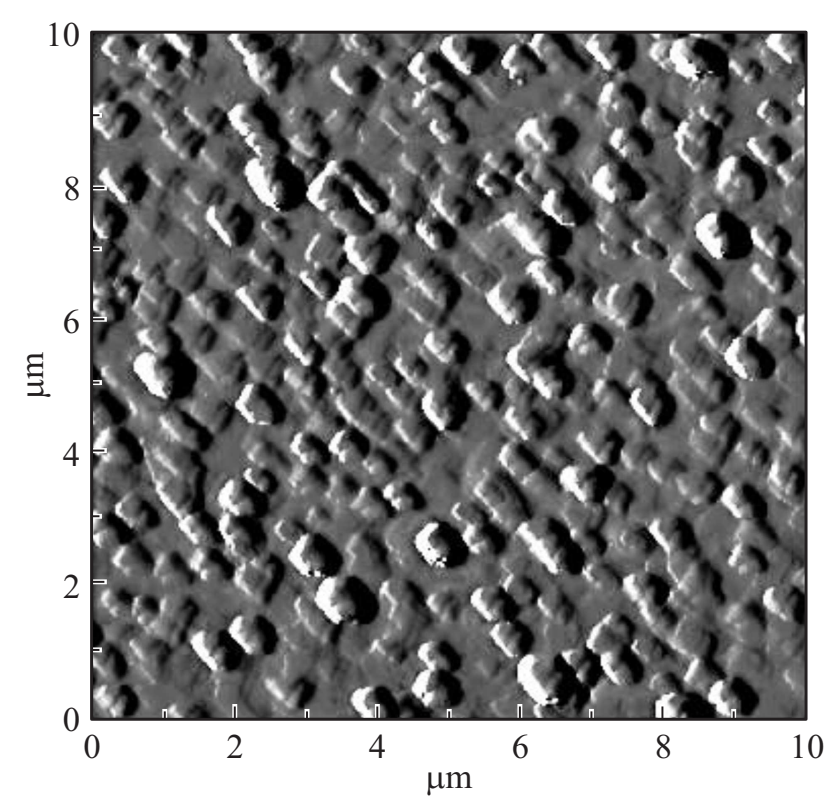

Рис. 1. АСМ-изображение структуры слюда- $\mathrm{Sb}$ (10 нм $)-\mathrm{Bi}$ $(640$ нм $)$, скан $10 \times 10$ мкм. 


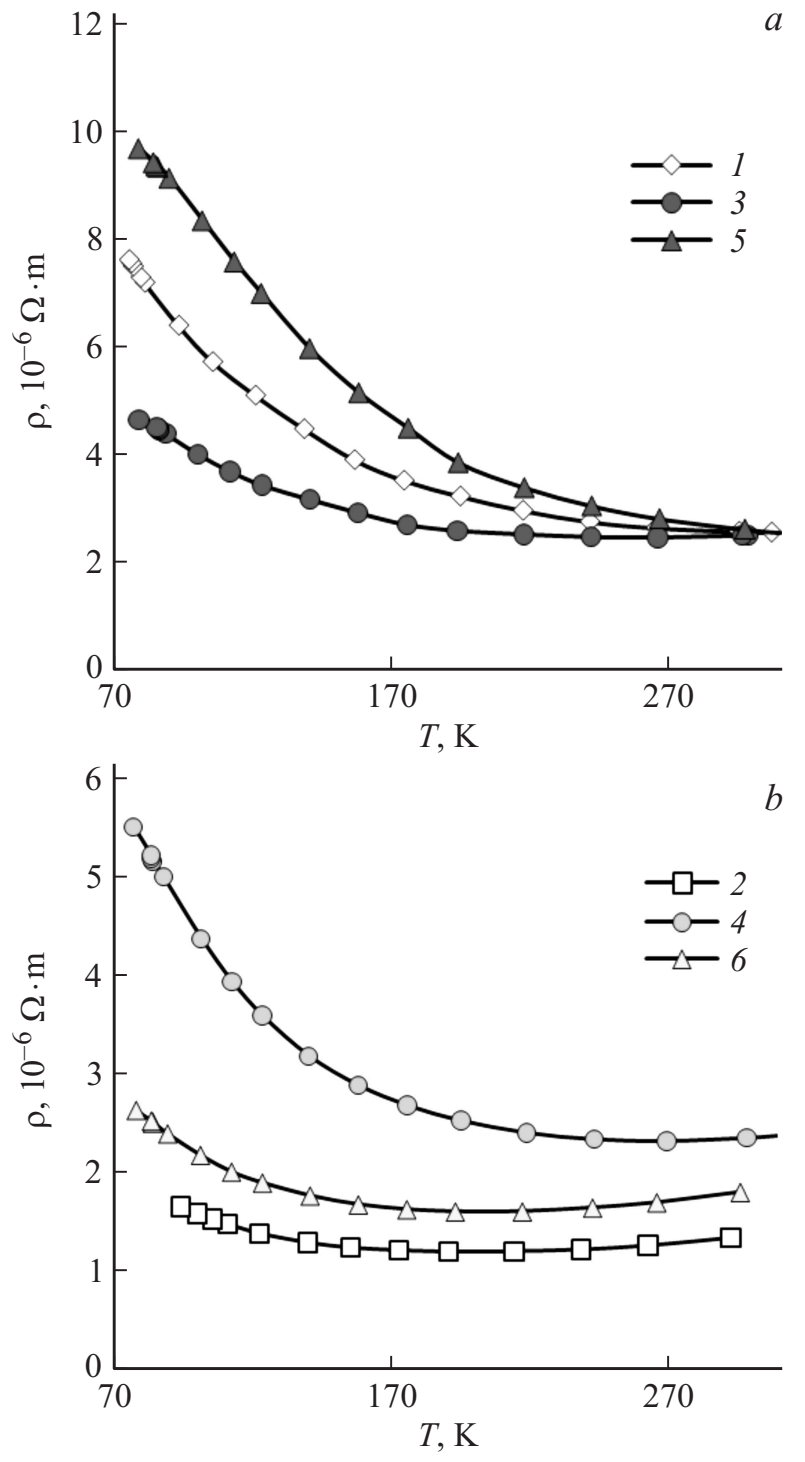

Рис. 2. Температурная зависимость удельного сопротивления структур с суммарной толщиной 90 нм (a) и 640 нм $(b)$ : 1 - слюда-Ві (90 нм), 2 - слюда-Ві (650 нм), 3 слюда-Sb (10 нм)-Bi (80 нм), 4 - слюда-Sb (10 нм)-Bi (640 нм $), 5$ - слюда-Вi (80 нм)-Sb (10 нм), 6 - слюда-Вi $(640 \mathrm{Hм})-\mathrm{Sb}(10 \mathrm{Hм})$.

фигуры роста. Это позволяет предположить, что ультратонкая пленка сурьмы имеет наноблочную структуру, и ее влияние на кристаллизацию висмута не должно оказывать существенного влияния.

Это предположение подтверждается данными АCMисследования слоистых структур типа подложка- $\mathrm{Sb}-\mathrm{Bi}$, представленными на рис. 1. Кристаллографическая ориентация блоков соответствует ориентации оси $C_{3}$ параллельно нормали плоскости пленки. Размеры кристаллитов немного меньше и составляют 0.5-7 мкм.

Исходя из анализа кристаллической структуры пленок, можно утверждать, что подслой сурьмы незначительно уменьшает размеры блоков, но качественно не изменяет кристаллографическую структуру и ориентацию пленки.
Висмут и сурьма могут образовывать непрерывный ряд твердых растворов. При этом происходит существенное изменение зонной структуры вещества, а, следовательно, и его свойств. Чтобы убедиться в неизменности слоистой структуры после отжига, мы провели элементный анализ пленок, используя метод электронной растровой микроскопии. Исследование показало, что в процессе отжига не происходит проникновение атомов сурьмы в объем пленки висмута.

\section{2. Гальваномагнитные свойства и анализ результатов}

Температурные зависимости удельного сопротивления исследуемых слоистых структур на слюде представлены

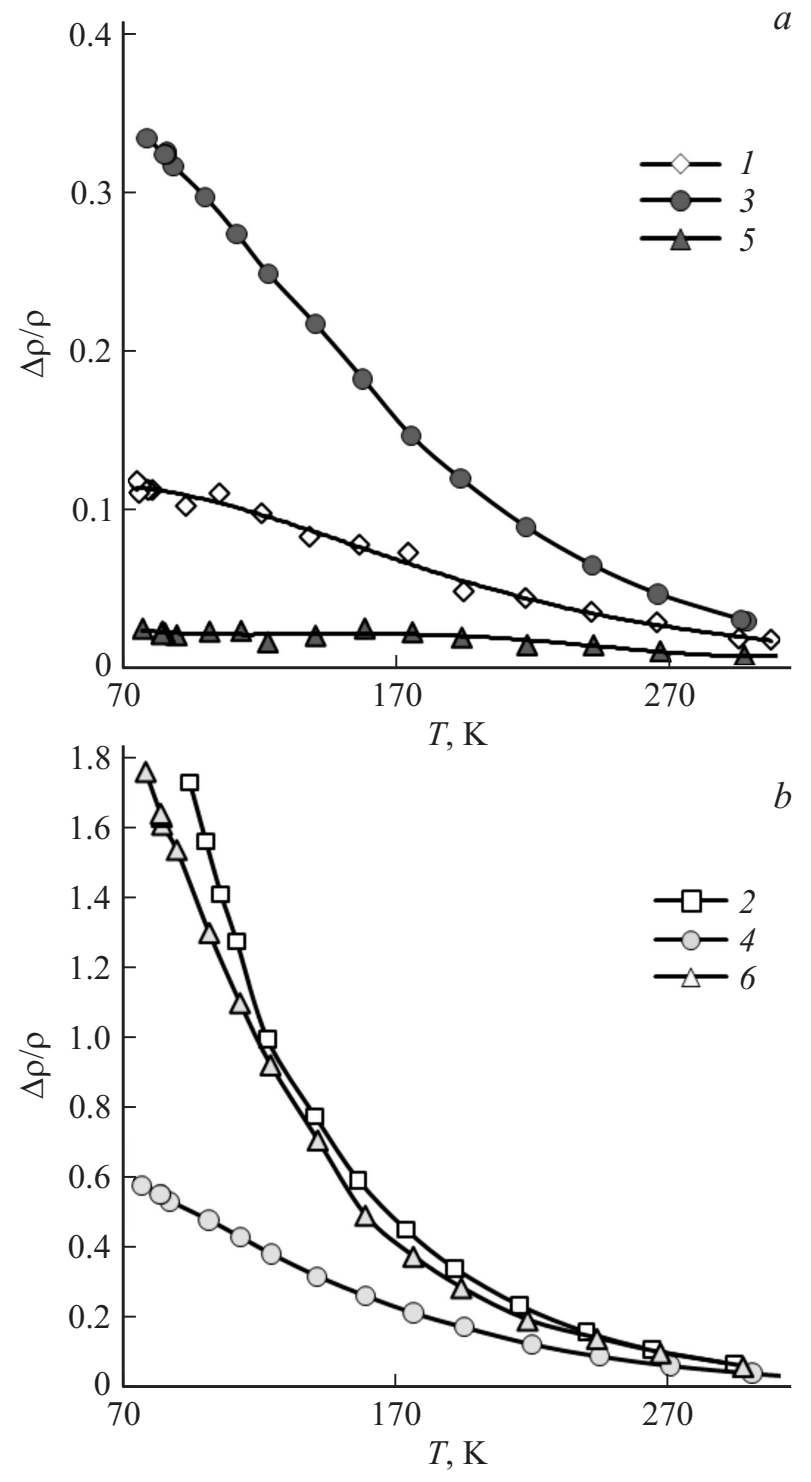

Рис. 3. Температурная зависимость относительного магнетосопротивления структур с суммарной толщиной 90 нм (a) и 640 нм $(b): 1$ - слюда-Ві (90 нм), 2 - слюда-Ві $(650$ нм), 3 - слюда - Sb (10 нм $)-\mathrm{Bi}(80$ нм $), 4-$ слюда $-\mathrm{Sb}(10$ нм $)-\mathrm{Bi}$ (640 нм), 5 - слюда-Вi (80 нм)-Sb (10 нм), 6 - слюда-Вi (640 нм)-Sb (10 нм). 


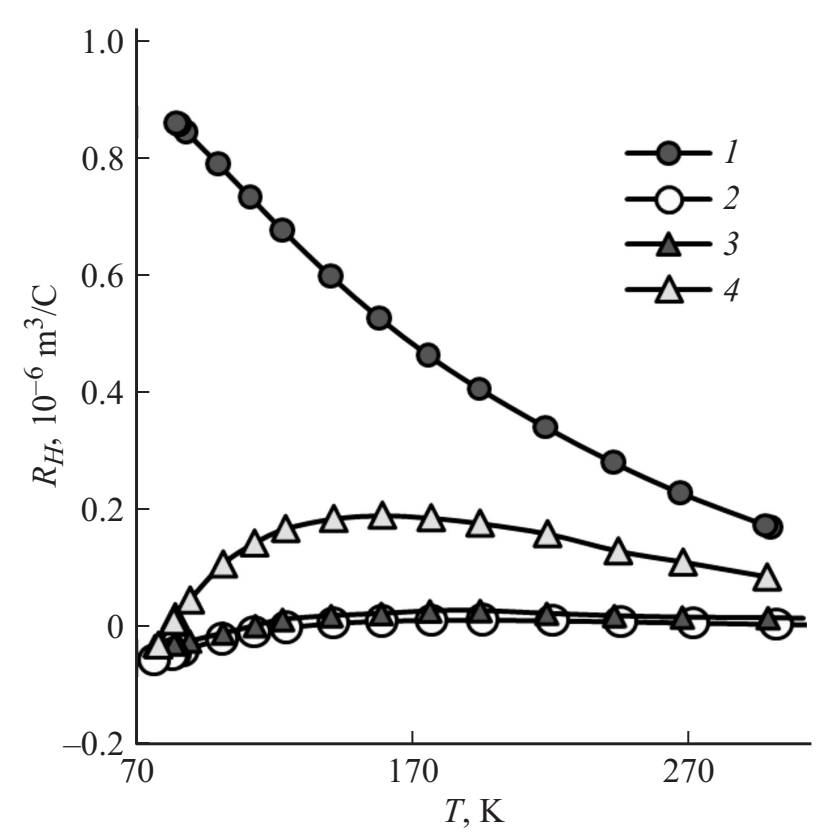

Рис. 4. Температурная зависимость коэффициента Холла структур: 3 - слюда-Sb (10 нм)-Bi (80 нм), 4 - слюда-Sb $(10 \mathrm{Hм})-\mathrm{Bi}(640 \mathrm{нм}), 5-$ слюда-Bi $(80 \mathrm{Hм})-\mathrm{Sb}(10 \mathrm{Hм}), 6-$ слюда-Bi (640 нм)-Sb (10 нм).

на рис. 2. Удельное сопротивление пленок с суммарной толщиной $\sim 90$ нм заметно больше, чем пленок с толщиной 640 нм, что связано с проявлением классического размерного эффекта.

Стоит отметить, что подслой сурьмы по-разному влияет на удельное сопротивление „толстой“ и „тонкой“ пленок висмута. В структурах толщиной $\sim 650$ нм слой сурьмы увеличивает сопротивление пленки вне зависимости от своего положения, но в разной степени. В более тонких же структурах подслой сурьмы уменьшает удельное сопротивление пленки висмута, а покрытие увеличивает его.

Температурные зависимости магнетосопротивления исходных пленок висмута и слоистых структур на их основе представлены на рис. 3. Пленки висмута толщиной $\sim 650$ нм, и структуры на их основе при всех температуpax имеют магнетосопротивление большее, чем тонкие структуры. Как и в случае удельного сопротивления, влияние слоя сурьмы на пленки висмута разной толщины не одинаковое. В структурах с общей толщиной $\sim 90$ нм использование подслоя сурьмы увеличивает значение магнетосопротивления, а использование слоя сурьмы в качестве покрытия уменьшает его в десятки раз по сравнению с магнетосопротивлением пленки без модификации поверхности. В структуре на основе „толстой“ пленки ( 640 нм), наоборот, подслой сурьмы значительно уменьшает магнетосопротивление, а покрытие слоем сурьмы практически не влияет на него.

Результаты измерения коэффициента Холла представлены на рис. 4. Влияние слоя сурьмы на коэффициент Холла пленочной структуры также значительно разли- чается в зависимости от его расположения и толщины пленки висмута.

Таким образом, проведенные исследования дали неожиданный результат: ультратонкий слой сурьмы (10 нм) по-разному изменяет свойства пленок висмута в зависимости от его положения (подслой или покрытие) и толщины пленки висмута. Использование простых моделей, таких как взаимное шунтирование сопротивления слоев, изменение коэффициента зеркальности взаимодействия носителей заряда с границами раздела, не позволяет объяснить полученные экспериментальные результаты. Возможно, механизм влияния имеет более глубинный характер. Для выявления причин обнаруженного влияния ультратонкого слоя сурьмы на свойства пленок висмута планируется проведение дальнейших исследований.

\section{4. Заключение}

Исследование кристаллической структуры пленок висмута как составной части слоистой структуры показало, что пленка сурьмы (10 нм) в качестве подслоя или покрытия не оказывает значительного влияния на кристаллическую структуру пленок висмута.

Исследования гальваномагнитных свойств пленок висмута и слоистых структур на основе пленок висмута и слоя сурьмы (10 нм) показали, что: использование слоя сурьмы в качестве подслоя или покрытия приводит к различным изменениям свойств структуры относительно исходных пленок висмута.

В структурах толщиной $\sim 650$ нм слой сурьмы увеличивает сопротивление пленки в не зависимости от своего положения, но в разной степени.

В более тонких структурах ( 90 нм) подслой сурьмы уменьшает удельное сопротивление пленки висмута, а покрытие увеличивает его.

Планируется проведение дополнительных систематических исследований с целью выявления механизмов обнаруженного эффекта.

Работа выполнена при финансовой поддержке Министерства образования и науки Российской Федерации.

\section{Список литературы}

[1] В.М. Грабов, В.А. Комаров, Н.С. Каблукова. ФТТ, 58 (3), 605 (2016).

[2] Н.С. Каблукова, В.А. Комаров, Е.В. Демидов, Е.Е. Христич. Изв. РГПУ им. А.И. Герцена, 153 (2), 13 (2012).

[3] Л.С. Палатник, М.Я. Фукс, В.М. Косевич. Механизм образования и субструктура конденсированных пленок (М., Наука, 1972) с. 320.

[4] В.М. Грабов, Е.В. Демидов, В.А. Комаров, М.М. Климантов, Д.Ю. Матвеев, С.В. Слепнев, Е.В. Усынин, Е.Е. Христич, Е.В. Константинов. Изв. РГПУ им. А.И. Герцена, 95, 105 (2009).

Редактор А.Н. Смирнов 


\section{Galvanomagnetic properties films of bismuth with thin coating or sublayer of antimony}

N.S. Kablukova, V.A. Komarov, D.O. Skantheko, E.S. Makarova, E.V. Demidov

The Herzen State Pedagogical University of Russia, 191186 St. Petersburg, Russia

Abstract The work studied the effect of surface modification thin films of bismuth antimony layer of thickness $10 \mathrm{~nm}$. We compared three types of structures on substrate of mica: bismuth film, antimony layer as the underlayer film of bismuth; a layer of antimony as a coating film of the bismuth. An important difference of the galvanomagnetic properties of the structures depending on the layer position of antimony in the structure and film thickness of the bismuth is shown. 